\title{
Nutritional and techno-functional properties of monofloral bee-collected sunflower (Helianthus annuus L.) pollen
}

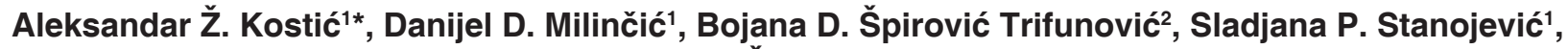 \\ Steva Lević1, Nebojša Nedić ${ }^{3}$, Viktor Nedović1, Živoslav Lj. Tešić4, Mirjana B. Pešić1 \\ ${ }^{1}$ University of Belgrade, Faculty of Agriculture, Chair of Chemistry and Biochemistry, Nemanjina 6, 11080 Belgrade, Serbia, ${ }^{2}$ University of \\ Belgrade, Faculty of Agriculture, Chair of Pesticides and Herbology, Nemanjina 6, 11080 Belgrade, Serbia, ${ }^{3}$ University of Belgrade, Faculty \\ of Agriculture, Chair of Breeding and Reproduction of Domestic and Bred Animals, Nemanjina 6, 11080 Belgrade, Serbia, ${ }^{4}$ University of \\ Belgrade, Faculty of Chemistry, Chair of Analytical Chemistry, Studentski Trg 12-16, 11000 Belgrade, Serbia
}

\section{A B S TR A C T}

\begin{abstract}
The aim of this study was to examine nutritional (total lipid, carbohydrate, protein and ash content, fatty acids and protein profile) and techno-functional properties of monofloral bee-collected sunflower pollen (Helianthus annuus L.). The content of water, total protein, carbohydrate, lipid and ash was 24.99, 14.36, 82.01, 1.62 and $2.01 \mathrm{~g} / 100 \mathrm{~g} \mathrm{DW}$, respectively, with the total energy value of 400.06 $\mathrm{kcal} / 100 \mathrm{~g} \mathrm{DW}$. The fatty acid profile revealed the presence of five fatty acids with the stearic acid as dominant one (31.4\%) followed by $\alpha$-linoleic $(20.7 \%)$, pentadecanoic $(18.2 \%)$, heneicosanoic $(17.1 \%)$ and palmitic $(12.5 \%)$ acids. FTIR analysis of bee pollen grains confirmed the presence of the main pollen chemical constituents such as proteins, water, carbohydrates and lipids, but also the presence of sporopollenin and polyphenols. Raman spectroscopy analysis indicated that the surface of pollen grains was rich in carotenoids. Low protein (3.64 g/100g DW) but high carbohydrate (77.09 g/100 g DW) solubility of bee pollen was observed. The good emulsifying properties (ESI, $19.98 \mathrm{~min}$; EAI, $\left.80.54 \mathrm{~m}^{2} / \mathrm{g}\right)$ and excellent oil $(2.43 \mathrm{~g} / \mathrm{g} \mathrm{DW})$ but poor water $(0.87 \mathrm{~g} / \mathrm{g}$ DW) absorption capacities were also registered. On the other hand, the sunflower bee pollen did not show foaming properties. These findings indicate to its applicability as useful nutritional, lipophilic and anti-foaming food ingredients.
\end{abstract}

Keywords: Fatty acids; Helianthus annuus L.; Monofloral bee-collected pollen; Proteins; Techno-functional properties

\section{INTRODUCTION}

Bee-collected pollen is known as an excellent source of almost all necessary macro- and micronutrients. Depending on its botanical and/or geographical origin chemical composition can vary but, in general, the most abundant components in pollen are sugars (13-55\%), proteins (10-40\%) and lipids (up to 13\%) (Campos et al., 2008). Furthermore, pollen contains significant quantities of different chemical elements (ash content is in range from 2 to $6 \%$ ) (Campos et al., 2008) with particular emphasis on considerable iron and zinc content (Serra-Bonvehí and Escolá Jordá, 1997; Kostić et al., 2015a). Pollen proteins contain all amino acids essential to humans (presented in free form or released during hydrolysis) increasing its nutritional value (Thakur and Nanda, 2020). Besides the simple ones (albumins, globulins, glutelins and prolamines), proteins from pollen grain can be conjugated with other important biomolecules such as nucleic acids, sugars and lipids (Kieliszek et al., 2018). Lipid pollen fraction is an important segment of one of the pollen surface membranes - exine, constituting a crucial part of sporopollenin polymer network (Ischebeck, 2016). Due to stability of sporopollenin these lipids probably will be inaccessible as nutrients. In addition, during the final phase of pollen grain formation, at the surface of exine, special, so-called pollenkitt zone is formed (Dobson, 1988; Ischebeck, 2016). This zone is characterized by accumulation of different chemical compounds (among them there are significant parts of different lipophilic substances) with responsibility for pollen protection and interaction with pollinators in the form of attractants (Ischebeck, 2016) as well as receptor molecules for communication between pollen grain and stigma during pollination process (Wolters-Arts et al., 1998; Zinkl and

\footnotetext{
${ }^{*}$ Corresponding author:

Aleksandar Ž. Kostić, University of Belgrade, Faculty of Agriculture, Chair of Chemistry and Biochemistry, Nemanjina 6, 11080 Belgrade, Serbia. E-mail: akostic@agrif.bg.ac.rs
} 
Preuss, 2000). Free fatty acids, hydrocarbons, long chain alcohols, esters, carotenoids and terpenes are the main lipophilic substances biosynthesized in the pollen grain but deposited in its surface zone. On the other side, polar lipids (components of cell membranes) and neutral lipids (in the form of triacylglicerides (TAGs) are mostly concentrated in the inner part of the grain (Dobson, 1988; Ischebeck, 2016). Such complex system like pollen is can be examined through application of Raman and infrared spectroscopy which allow identification of different biomolecules (sugars, lipids, etc.) presented in plant cell (Wiercigroch et al., 2017). Previous researches have proved that these techniques are applicable in case of pollen (Schulte et al., 2008; Zimmermann and Kohler, 2014; Buta et al., 2015; Anjos et al., 2017). Along with sugars, lipids and proteins are the main food components which determine and define technofunctional properties of food products (Foegeding and Davis, 2011; Karakashev and Grozdanova, 2012; Evans et al., 2013; Gould et al., 2016). Thus, the potential use of bee pollen in the formulation of food products as a functional additive or ingredient requires the definition of its technofunctional properties. Considering the multicomponent and complex chemical composition of bee pollen, particular attention should be paid to proteins, lipids and sugars when interpreting functional properties. Protein solubility is often highlighted as a key factor in considering the functionality of natural food supplements, since it affects other properties such as emulsifying, foaming, gelling, water and oil binding capacity (Kinsella and Melachouris, 1976). Literature search has shown lack of data about techno-functional properties of pollen. In fact there have been only two previously published articles (Kostić et al., 2015b; Thakur and Nanda, 2019). However, it was reported that bee-collected pollen possesses excellent emulsifying properties (Kostić et al., 2015b; Thakur and Nanda, 2019). Additionally, depending on their botanical origin, different samples have good oil and poor water absorption capacities. All of these justify additional and further research about this topic. To define precise chemical composition of pollen is to possess a monofloral pollen sample, a sample which contains more than $80 \%$ of one pollen grain type (Campos et al., 2008). Thus, the study of the nutritional and techno-functional properties of monofloral bee-collected sunflower (Helianthus annuиs L.) pollen can help to estimate the potential use of bee-collected pollen as valuable food ingredient.

In this sense, the aims of this research were as follows: 1) to determine the physicochemical composition of monofloral bee-collected sunflower (Helianthus annuns L.) pollen, such as total protein, lipid, carbohydrate and ash contents; 2) to determine fatty acid profile based on gas-chromatography analysis (GC); 3) to determine the chemical composition of bee pollen grains, especially the occurrence of different lipophilic components (carotenoids) based on FTIR and
Raman spectra data; 4) to assess, for the first time, technofunctional properties (protein and carbohydrate solubility, emulsifying and foaming properties, water and oil absorption capacity) of monofloral sunflower bee-collected pollen.

\section{MATERIAL AND METHODS}

\section{Pollen collection}

The sample of pollen was collected during sunflower bee pasture in June 2017 in the locality of Uljma, in the region of Banat which is the main region for production of sunflower in the Republic of Serbia. On an apiary the two bee colonies equalized in strength were chosen and the pollen traps were placed at the hives entrance. Pollen traps were activated 5 days before the main sample was taken and pollen was collected from pollen traps every day after which the traps were thoroughly cleaned. The sample for analysis was taken on the sixth day when the pollen was being collected, at the end of a day from both traps, and then was carefully mixed to equalize in order to obtain one representative sample. Up to the time of the analysis the pollen bulk was kept in a plastic vacuum bag wrapped in aluminum foil and stored in a freezer at the temperature of $-20^{\circ} \mathrm{C}$. Preparation of sample for palynological analysis was described in our previous research (Kostić et al., 2015b). On the basis of a microscopic analysis of 500 pollen grains a predominant percentage of pollen grains of Helianthus annuus (80.4\%) was determined. Pollen grains of Taraxacum officinale (14.6\%) were present as important minor pollen, as well as the pollen grains of plants from the Rosaceae family ( $5 \%$ ). On the basis of melisopalynological analysis the sample can be characterized as a monofloral sunflower pollen.

\section{Determination of physicochemical composition and total energy of sunflower bee-collected pollen}

Total protein, lipid, carbohydrate and ash content as well as moisture content were determined according to methodology defined in our previous investigation (Kostić et al., 2015b). All obtained results are expressed as $\mathrm{g} / 100 \mathrm{~g}$ of dry weight of the bee-collected pollen sample, except in the case of moisture content ( $\mathrm{g} / 100 \mathrm{~g}$ of fresh bee-collected pollen sample). Based on the obtained results for proximate chemical composition, calculation for total energy of bee-collected pollen was made (Kostić et al., 2015b). The result is expressed as kcal/100 g.

\section{Analysis of fatty acid composition of sunflower bee-collected pollen}

The bee pollen extract, which contains fatty acids (FAs), was prepared according to our previously reported method (Kostić et al., 2017). After that, FA esterification and GC analysis were conducted (Kostić et al., 2017). The content of fatty acids is defined as $\%(\mathrm{~g} / 100 \mathrm{~g})$ of total fatty acids expressed per dry weight of the sample. 


\section{FTIR analysis of sunflower bee-collected pollen}

Fourier transform infrared spectroscopy (FTIR) analysis of pollen grains was performed using $\mathrm{KBr}$ pastille method. The sample was mixed with potassium bromide, crushed and compressed to pastille. Infrared spectra over the wavelength range of $4000-400 \mathrm{~cm}^{-1}$ were recorded with an IRAffinity-1 F'TIR spectrophotometer (Schimadzu, Japan). The measurement resolution was $4 \mathrm{~cm}^{-1}$.

\section{Raman spectroscopy of sunflower bee-collected pollen sample}

Raman spectra of the sunflower pollen were collected with XploRA Raman spectrometer (Horiba Jobin Yvon). The analyses were performed using a laser at $532 \mathrm{~nm}$. The measurement conditions were applied in accordance with literature data, aiming to avoid sample damage due to laser exposure (Withnall et al., 2003). All measurements were realized using the $50 \times$ long working distance objective and spectrometer equipped with a $2400 \mathrm{gr} / \mathrm{mm}$ grating.

\section{SDS-PAGE electrophoresis}

Electrophoresis of protein fraction under reducing conditions was conducted as it is described in our previous research (Kostić et al., 2015b).

\section{Determination of techno-functional properties of sunflower bee-collected pollen}

The examined techno-functional properties (protein and carbohydrate solubility, emulsifying and foaming properties as well as water and oil absorption capacity) were determined as described in our previous investigation (Kostić et al., $2015 b)$. Solubility of proteins and carbohydrates are expressed as the content $(\mathrm{g} / 100 \mathrm{~g})$ of soluble fractions of these compounds compared to the total protein and carbohydrate contents. Emulsion stability index (ESI) is calculated in minutes while emulsion activity index (EAI) is defined as $\mathrm{m}^{2} / \mathrm{g}$. Water (WAC) and oil (OAC) absorption capacity is given as $\mathrm{g} / \mathrm{g}$ of sample.

\section{Statistical analysis}

All data was reported as the mean values of three replications and expressed as mean \pm SD. The Statistical softwer Satistica ver. 8.0 (StatSoft. Inc., Tulsa, OK, USA) was used to analyze the differences among the means by t-test with significant differences at $p<0.05$.

\section{RESULTS AND DISCUSSION}

\section{Physicochemical composition of monofloral sunflower bee-collected pollen and total energy value}

The content of moisture, total protein, lipid, carbohydrate and ash are given in Table 1. The main components in the pollen sample are carbohydrates (around 81\%) followed by moisture, proteins, ash and lipids. Total protein content
Table 1: Physicochemical composition of bee-collected monofloral sunflower pollen sample

\begin{tabular}{lc}
\hline Parameter & Measured value $\pm \mathrm{SD}^{1}$ \\
\hline Moisture content $(\mathrm{g} / 100 \mathrm{~g} \mathrm{FW})$ & $24.99 \pm 0.20$ \\
Ash content ( $\mathrm{g} / 100 \mathrm{~g} \mathrm{DW})$ & $2.01 \pm 0.04$ \\
Total protein content $(\mathrm{g} / 100 \mathrm{~g} \mathrm{DW})$ & $14.36 \pm 0.10$ \\
Total carbohydrate content $(\mathrm{g} / 100 \mathrm{~g} \mathrm{DW})$ & $82.01 \pm 0.16$ \\
Total lipid content $(\mathrm{g} / 100 \mathrm{~g} \mathrm{DW})$ & $1.62 \pm 0.02$ \\
Total energy ( kcal/100 g) & $400.06 \pm 20.27$ \\
\hline${ }^{1}$ The results in the table are presented as means \pm standard deviations $($ mean $\pm S D ;$ \\
$\mathrm{n}=3)$. All the obtained results were significantly different, $t$-test, $(p<0.05)$
\end{tabular}

and total ash content were fully in line with the results for bee-collected sunflower pollen from South Africa $14.21 \%$ and $1.61 \%$, respectively (Nicolson and Human, 2013). The result for total protein content was similar to that of sunflower bee-collected pollen from Saudi Arabia $15.19 \%$ (Taha et al., 2019) and Italy (16.50\%) (Conti et al., 2016), while total carbohydrate content for the Italian sample was significantly lower (45.15\%). The observed differences could be provoked with different environmental conditions as well as different sunflower varieties used for analysis. The total lipid content was significantly lower compared to bee-collected pollen from South Africans' sunflower variety $-5.47 \mathrm{~g} / 100 \mathrm{~g}$ (Nicolson and Human, 2013). These variations can be attributed to the different geographical origin and/or growing conditions or different sunflower varieties used as pollen source (Nicolson and Human, 2013; Conti et al., 2016; Taha et al., 2019). High average carbohydrates content $(82.01 \%)$ was documented in majority of pollen samples (more than $80 \%$ ) examined by Kostić et al. (2015b). Importance of palynological origin of pollen is clearly emphasized in the study of Avni et al. (2014) who found that proteins content in pollen can vary from 10.60 to $73.00 \%$. The water content registered in the analyzed sample is in line with the results for bee-collected sunflower pollen sample from the South-Africa - 19.78\% (Nicolson and Human, 2013).

This value is expected for fresh pollen due to its ability to absorb air moisture (Belina-Aldemita et al., 2019) but it should be reduced before any further processing since it makes ideal conditions for microbial growth and spoilage of the sample. In this regard, some different drying methods can be applied - sun drying in controlled conditions, hot-air drying or sample lyophilization. According to several official legislations (Argentina, Serbia, China), water content in bee-collected pollen should be in the range between 4 and 10\% (Krell, 1996; GB/T, 2003; OGRS, 2013).

Based on the content of proteins, lipids and carbohydrates, total energy assessment of sunflower bee-collected pollen was conducted and it was $400.06 \mathrm{kcal} / 100 \mathrm{~g} \mathrm{DW}$ (e.g. 1673.8 kJ/100 g DW). Precisely, 57.4 kcal/100 g DW, 
$14.6 \mathrm{kcal} / 100 \mathrm{~g} \mathrm{DW}$ and $328.1 \mathrm{kcal} / 100 \mathrm{~g} \mathrm{DW}$ originated from proteins, lipids and carbohydrates, respectively. The total energy of bee pollen sample analysed in this study was slightly higher compared to those obtained for different bee pollen samples collected in Serbia, which were in range from 350 to $396 \mathrm{kcal} / 100 \mathrm{~g}$ (Kostić et al., 2015b). According to Food and Agriculture Organization of United Nation (FAO) during food intake, energy distribution should be arranged in such a way that $10-12 \%$ of obtained energy is derived from proteins, $30 \%$ should be ascribed to lipids from food and around $60 \%$ should be connected with sugars. After comparing this with the findings in the current study (14.4\% of energy is provided from proteins, $3.6 \%$ from lipids and $82 \%$ from sugars), it can be observed that there is inadequate distribution of energy compounds.

Fatty acids content of bee-collected sunflower pollen Table 2 defines the determined fatty acids profile based on the results of GC analysis of the bee pollen sample.

Similar to Nicolson and Human (2013) who found only eight different FAs in sunflower bee-collected pollen, merely five different fatty acids were quantified in the examined sample (Table 2). Besides, additional thirty-two fatty acids were monitored but the results were below limit of detection. It was observed that the most predominant FA in the sunflower bee-collected pollen sample was stearic acid followed by $\alpha$-linoleic, pentadecanoic, heneicosanoic and palmitic acids. Likewise, Human and Nicolson (2013) have determined also a significant prevalence of saturated fatty acids (SFAs) compared to unsaturated ones (UFAs) but with different FAs distribution and share of fatty acids to their total amount. Unlike the analyzed pollen sample, in the bee-collected sunflower pollen from South Africa lauric and palmitic acids were the major ones. On the other hand, among UFAs, $\alpha$-linoleic acid was predominant in both cases. The observed differences could be related to different geographical origin, weather growing conditions and/or genetic variabilities. Based on UFA/SFA ratio value

Table 2: Fatty acids profile of bee-collected monofloral sunflower pollen sample

\begin{tabular}{lcc}
\hline Fatty acid (FA) & Label & $\begin{array}{c}\text { Share of total FAs } \\
(\% \pm S D)^{1}\end{array}$ \\
\hline Pentadecanoic acid & C15:0 & $18.24 \pm 0.58^{1}$ \\
Palmitic acid & C16:0 & $12.53 \pm 0.92$ \\
Stearic acid & C18:0 & $31.42 \pm 1.58$ \\
Heneicosanoic acid & C21:0 & $17.06 \pm 0.29$ \\
Total saturated fatty acids & SFAs & 79.25 \\
$\alpha$-Linoleic acid & C18-3n:3 & $20.75 \pm 1.62$ \\
Total polyunsaturated fatty & PUFAs & 20.75 \\
acids & UFA/SFA ratio & 0.26 \\
\hline
\end{tabular}

1 The results in the table are presented as means \pm standard deviations $($ mean $\pm S D ; n=3)$; All the obtained results were significantly different, $t$-test, $(\mathrm{p}<0.05)$
(0.26; Table 2), the examined sample show significantly lower value compared to the values observed for maize floral pollens from Serbia (Kostić et al., 2017) - which were in the range from 0.80 to 3.70 .

\section{FTIR pollen analysis}

The spectrum of sunflower bee-collected pollen grains shows the bands that correspond to the main pollen chemical constituents such as proteins (characteristic bands at 1635 and $1543 \mathrm{~cm}^{-1}$ ), water (characteristic band at $3383 \mathrm{~cm}^{-1}$ ), sugars (characteristic band at $1076 \mathrm{~cm}^{-1}$ ) and lipids (characteristic band at $1741 \mathrm{~cm}^{-1}$ ) (Fig. 1).

The strong band at $3383 \mathrm{~cm}^{-1}$ is from $\mathrm{OH}$ vibrations and could originate from water present in the pollen sample. Bands at $2926 \mathrm{~cm}^{-1}$ and $2852 \mathrm{~cm}^{-1}$ are due to C-H vibrations in polysaccharides, protein and lipid compounds (Depciuch et al., 2016). Low intensity band at $1741 \mathrm{~cm}^{-1}$ could be related to $\mathrm{C}=\mathrm{O}$ vibrations of lipids. Similarly, the band at $1745 \mathrm{~cm}^{-1}$, which originates from lipids, was recorded in Atlas cedar (Cedrus atlantica), Pennsylvanian ash (Fraxinus pennsylvanica) and Carniolian lily (Lilium carniolicum) pollen samples (Zimmermann and Kohler, 2014). The two bands at $1635 \mathrm{~cm}^{-1}$ and $1543 \mathrm{~cm}^{-1}$ are in agreement with literature, and probably derived from amide I (carbonyl group) and amide II (N-H and C-N bonds) groups stretching in the protein structure, respectively (Zimmermann and Kohler, 2014). The band related to polygalacturonic acids COO vibrations is identified at $1417 \mathrm{~cm}^{-1}$. The presence of the polysaccharides may be confirmed by the strong band at $1076 \mathrm{~cm}^{-1}$ and by several small bands in the spectral region $800-900 \mathrm{~cm}^{-1}$ that occur due to C-O-C vibrations (Buta et al., 2015). According to some authors, presence of the signal at $817 \mathrm{~cm}^{-1}$ could be related to sporopollenin and ring vibrations caused by existence of phenylpropanoid

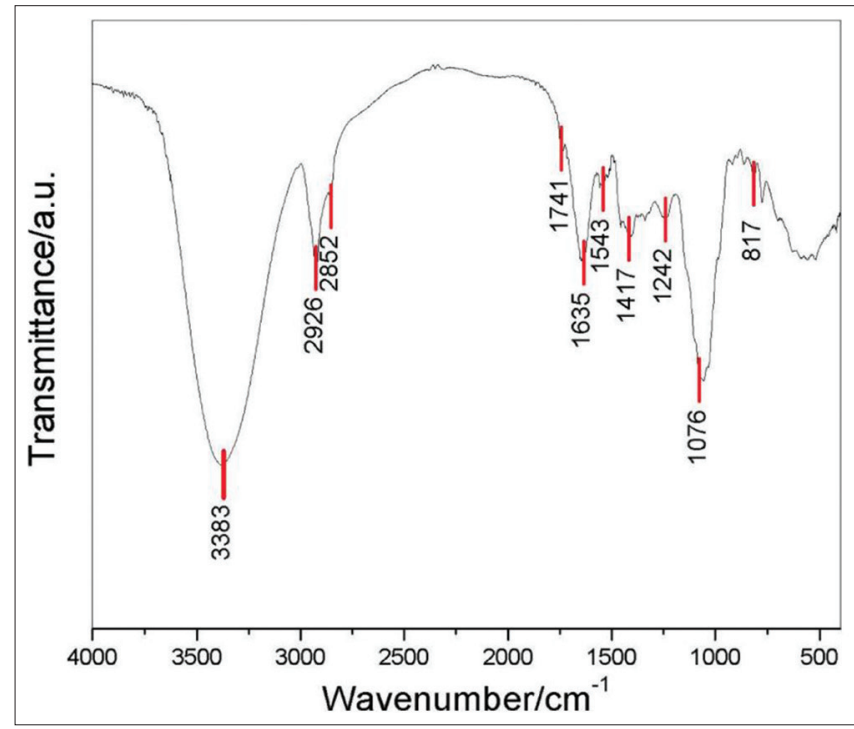

Fig 1. The FTIR spectrum of sunflower bee-collected pollen. 
units in this biopolymer (Schulte et al., 2008; Zimmermann et al., 2015). The same authors concluded that this type of sporopollenin mostly consists of ferulic building units. In addition, some of the observed bands with wavenumbers between 800 and $1500 \mathrm{~cm}^{-1}$ could originate from present phenolic compounds as the result of C-C and C-O bond vibrations (Anjos et al., 2017).

\section{Raman spectroscopy of monofloral sunflower bee- collected pollen sample}

The Raman spectrum of the sunflower bee-collected pollen (Fig. 2) indicates that the surface of pollen grains is rich in carotenoids.

The main bands that occur due to these compounds are $1154 \mathrm{~cm}^{-1}$ (stretching C-C vibrations), $1519 \mathrm{~cm}^{-1}$ (stretching $\mathrm{C}=\mathrm{C}$ vibrations) and $1004 \mathrm{~cm}^{-1}$ (C-C vibrations) (Schulz and Baranska, 2007). In addition, band at $1154 \mathrm{~cm}^{-1}$ could be provoked by coupling of the $\mathrm{CO}$ and $\mathrm{CC}$ stretches of hexoses (Wiercigroch et al., 2017). The medium strong band at the same shift $\left(1519 \mathrm{~cm}^{-1}\right)$ was recorded in the Raman spectra of Viburnum opulus pollen (Guedes et al., 2014) while the maize pollen (Zea mays) and ray grass (Lolium perenne) showed very strong bands at $1528 \mathrm{~cm}^{-1}$. In the case of the band at $1154 \mathrm{~cm}^{-1}$ the same band (but with very low intensity) was recorded for the pollen of Mediterranean dwarf palm (Chamaerops humilis) (Guedes et al., 2014). The same authors confirmed similar strong bands in the spectra of grey willow (Salix atrocinerea) pollen $-1163 \mathrm{~cm}^{-1}$. The bands at $1438 \mathrm{~cm}^{-1}, 1188 \mathrm{~cm}^{-1}, 1004 \mathrm{~cm}^{-1}$ and $959 \mathrm{~cm}^{-1}$ are due to the presence of carotenoids, proteins and lipids, and they were also observed in the Raman spectra of the pollen from various plant species (Buta et al., 2015).

\section{Techno-functional properties of monofloral sunfower bee-collected pollen \\ Protein and carbohydrate solubility}

Protein solubility in the tested sunflower bee-collected pollen sample was 3.64 $\pm 0.005 \mathrm{~g} / 100 \mathrm{~g}$ DW (Table 3). This value is in the range of the results previously reported for the protein solubility of bee pollen samples collected in Serbia (from 2.79 to $25.9 \mathrm{~g} / 100 \mathrm{~g}$ ) (Kostić et al., 2015b). However, the result obtained in this investigation is significantly lower than in the samples analyzed in the previous study (Kostić et al., 2015b) in which sunflower (Helianthus annuus L.) was predominant (75\%) or accompanying types of pollen $(21 \%)$, with protein solubility of $19.27 \mathrm{~g} / 100 \mathrm{~g}$ and $25.90 \mathrm{~g} / 100 \mathrm{~g}$, respectively.

These differences could be due to different geographical origin of pollen samples, different accompanying plant species and/or the different year of pollen harvesting. Moreover, protein solubility depends on the amino acid composition, structure and conformation (e.g., surface

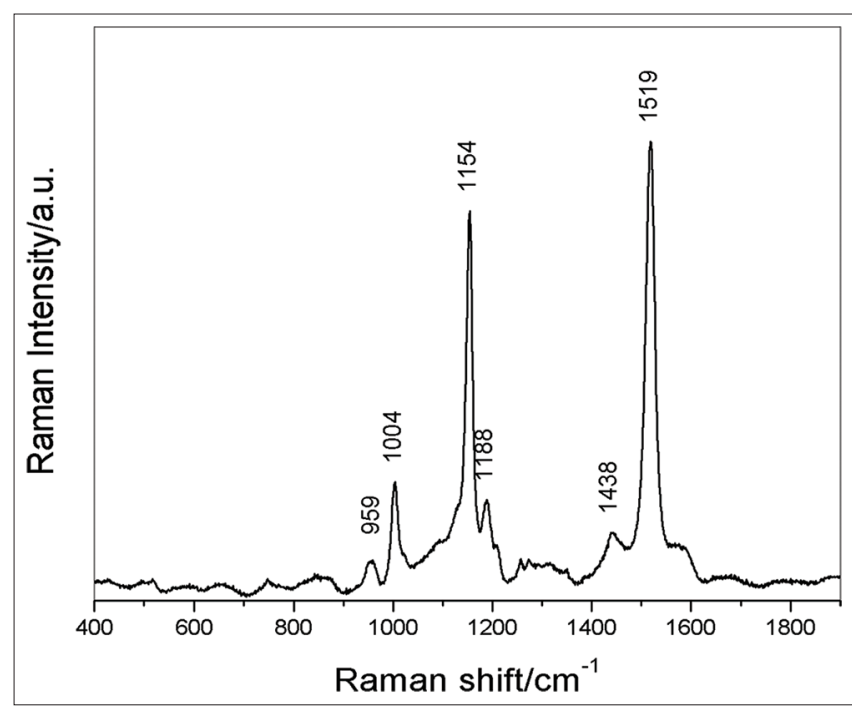

Fig 2. Raman spectra of monofloral sunflower bee-collected pollen.

Table 3: Techno-functional properties of sunflower beecollected pollen (Helianthus annuus L.)

\begin{tabular}{lc}
\hline Parameter & Measured value \pm SD \\
\hline Protein solubility $(\mathrm{g} / 100 \mathrm{~g} \mathrm{DW})$ & $3.64 \pm 0.005^{1}$ \\
Carbohydrate solubility $(\mathrm{g} / 100 \mathrm{~g} \mathrm{DW})$ & $77.09 \pm 0.27$ \\
$\mathrm{ESI}(\mathrm{min})^{2}$ & $19.98 \pm 1.70$ \\
$\mathrm{EAI}\left(\mathrm{m}^{2} / \mathrm{g}\right)^{2}$ & $80.54 \pm 3.52$ \\
WAC $(\mathrm{g} / \mathrm{g})^{2}$ & $0.87 \pm 0.01$ \\
OAC $(\mathrm{g} / \mathrm{g})^{2}$ & $2.43 \pm 0.02$ \\
WOAI $^{2}$ & $0.357 \pm 0.001$ \\
\hline
\end{tabular}

${ }_{1}$ The results in the table are presented as means \pm standard deviations $($ mean $\pm S D ; n=3) ;{ }^{2}$ ESI-Emulsion stability index; EAI-Emulsion activity index; WAC-Water absorption capacity; OAC-Oil absorption capacity; WOAI-Water-oil absorption index

hydrophobicity) of the proteins, interactions that can occur between proteins and other compounds (e.g., lipids, carbohydrates, polyphenols, and salts) as well as the $\mathrm{pH}$ of the environment (Culbertson, 2005; Boye et al., 2010). In order to gain a better insight in the composition of soluble proteins and their functionality, the study is accompanied by electrophoretic analysis (Fig. 3a). The soluble protein profile of sunflower bee pollen separated on SDS-PAGE under reducing conditions is presented in Figure $3 \mathrm{a}$. Several protein bands with higher or lower intensity can be noticed, in the molecular weights (MWs) range of 10 to $100 \mathrm{kDa}$. The major bands with MWs of 55.80; 41.40; $34.20 ; 31.60$ and $28 \mathrm{kDa}$ can be clearly observed, while the other detected bands were diffused and with lower intensity.

For easier interpretation and overview of the results, as well as to establish the relationship with other techno-functional properties, the relative composition of soluble proteins is expressed as four proteins MWs ranges: higher than $80 \mathrm{kDa}$, $80-50 \mathrm{kDa}, 50-25 \mathrm{kDa}$ and $>$ lower than $25 \mathrm{kDa}$ (Fig. 3b). Most of the soluble proteins were detected in the MWs range of $50-25 \mathrm{kDa}$, representing $55.31 \%$ of total soluble 
proteins, while proteins with MWs higher than $80 \mathrm{kDa}$, 80 $50 \mathrm{kDa}$ and lower than $25 \mathrm{kDa}$ contributed with $15.75 \%$, $19.78 \%$ i $9.16 \%$, respectively. These results are comparable with the results of Kostic et al. (2015b) obtained for 26 bee pollen samples collected in Serbia. It was found that bee pollen fractions with MWs of $80-50 \mathrm{kDa}, 50-25 \mathrm{kDa}$ and $25-$ $10 \mathrm{kDa}$ represent $13.40-32.20 \%, 22.20-43.60 \%$ and 32.90 $-63.40 \%$ of the total detected soluble proteins, respectively. The analysed bee pollen sample showed good carbohydrate solubility (77.09 g/100 g DW). Good carbohydrate solubility is expected due to high level of carbohydrates registered in sample. This value is slightly higher from the value registered in polyfloral bee-collected pollen sample from Vojvodina (Petrovaradin) - 75.00 g/100 g DW (Kostić et al., 2015b).

\section{Emulsifying properties}

Emulsions play a key role in the formulation and acceptability of foods. Thus, food products consisting of emulsions (e.g. mayonnaise, dressings, infant formulae, coffee creamers, cream liquers or some meat products) require to be prepared in a special way to ensure the stability of the emulsion droplets and to prevent reactions such as flocculation and aggregation over a long period of time (Dalgleish, 1997). Parameters such as emulsifying stability (ESI) and emulsifying activity (EAI) often serve to evaluate the emulsifying properties of numerous food constituents. The appearance and stability of prepared emulsion are presented at Fig. 4. The values obtained for the EAI and ESI parameters for the monofloral sunflower bee-collected pollen sample were $80.54 \pm 3.52 \mathrm{~m}^{2} / \mathrm{g}$ and $19.98 \pm 1.70 \mathrm{~min}$, respectively (Table 3).

The obtained ESI value was in the range of previously published results for bee pollen samples collected in Serbia (from 19.6 to $49.3 \mathrm{~min}$ ), while the EAI value was significantly higher than those reported in the same study (from 10.37 to $24.52 \mathrm{~m}^{2} / \mathrm{g}$ ) (Kostić et al., 2015b). In addition, the results obtained in this study are in accordance with the data

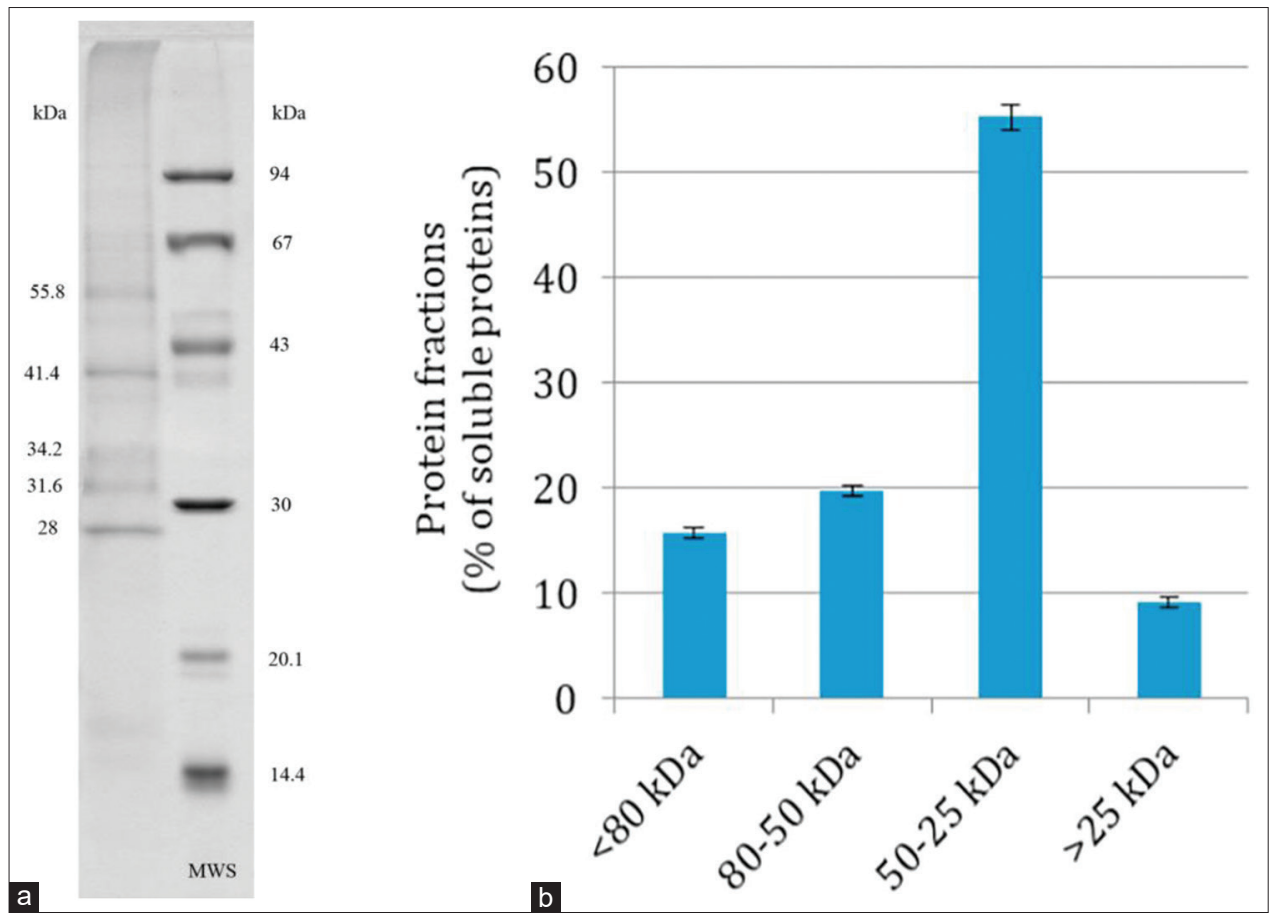

Fig 3. a) SDS-PAGE analysis of pollen sample; MWS - molecular weight standards b) The relative composition of soluble proteins of sunflower bee-collected pollen (Helianthus annuus L.) (mean $\pm S D ; n=3)$.
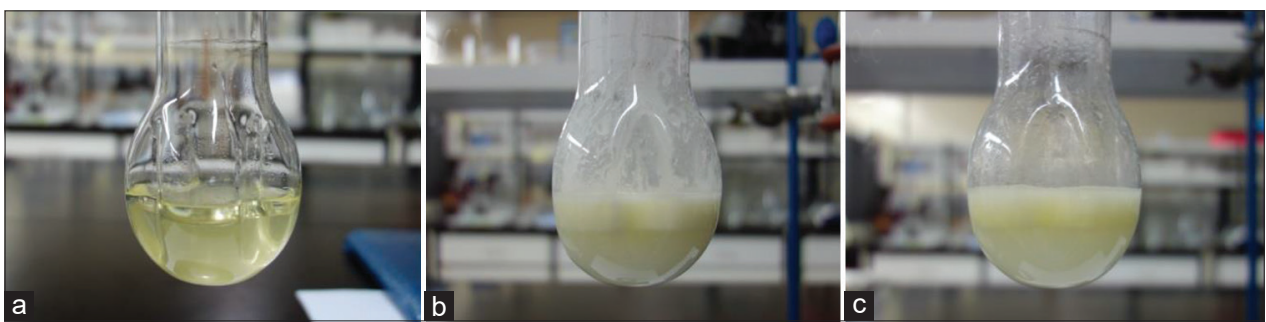

Fig 4. Methodological approach in determining of emulsifying properties of bee-collected sunflower (Helianthus annuus L.) pollen: (a) emulsion of pure sunflower oil and aqueous dispersion of pollen sample; (b) emulsion after homogenised for 1 min on high speed homogenizer; (c) emulsion stability after $10 \mathrm{~min}$. 
registered for the EAI and ESI of adzuki, pea and soy beans protein isolated at different $\mathrm{pH}$ values, which are characterized by good emulsifying properties (Barać et al., 2010; Barać et al, 2012; Barać et al., 2015). Good emulsifying properties of bee-collected pollen can be related to the chemical structure of bee-collected pollen, which is a complex mixture of many substances among which, beside proteins, polar lipids such as diacilglycerols and phospholipids can significantly contribute (Liang et al., 2013; Kostić et al., 2015b). Kostić et al. (2015b) pointed out a positive influence of protein solubility and protein fractions with MWs of $50-25 \mathrm{kDa}$ on the stability of emulsions. The same authors assumed that proteins of lower molecular weight diffuse faster into the interface and are better absorbed to the oil/water interfaces. Also, during adsorption to oil/water interfaces, proteins change their native conformation depending on the hydrophobic interactions between the surface (interfacial material) and side chains of the amino acids in the proteins (Dalgleish, 1997).

\section{Foaming properties}

The ability to form and stabilize the foam is very important in the production of many food products (angel food cakes, sponge cakes, divinity-type confections, candy, meringue, soufflés, various whipped toppings, icings, fudges, icecreams), in order to maintain their texture for an extended period of time (Kinsella and Melachouris, 1976). It is known that the formation and stability of foam in food is mainly influenced by low molecular weight proteins that are rapidly absorbed at the formed air/water interfaces (Foegeding and Davis, 2011). The analyzed bee pollen sample did not produce foam under the tested conditions (Fig. 5).

This result is in agreement with previously reported data by Kostić et al. (2015b), which showed the absence of foaming properties of various bee pollen suspensions. It was already reported that lipids such as phospholipids and lipoproteins hinder formation of stable protein layers at the air/water interface (Kinsella and Melachouris, 1976; Wang and Kinsella, 1976; Phillips et al., 1989) and this could be a reason for inability of bee pollen suspensions to form foams (Kostić et al., 2015b). However, our result is in contrast to the results obtained for Indian bee pollen, which showed foaming properties (Thakur and Nanda, 2019). These differences could be due to several factors such as different methodology for foam production in our study compared to the study of Thakur and Nanda (2019) (air introduction into pollen suspension versus its whipping in a mixer blender), time of foam production (maximum 1 min versus $5 \mathrm{~min}$ ) different concentration of bee-collected pollen suspension ( $2 \%$ versus $3 \%$ ) and possibly different chemical composition of bee-collected pollen samples.

\section{Water absorption capacity}

Water absorption capacity (WAC) is usually based on the interaction of proteins with water and it is an important feature of some food products (Kinsella and Melachouris, 1976). The texture and sensory properties of the food product, especially during storage for a long period of time, are highly dependent on WAC of food ingredients. Water absorption capacity of monofloral sunflower bee pollen was $0.87 \pm 0.01 \mathrm{~g} / \mathrm{g}$ (Table 3). This value is higher than that obtained by Thakur and Nanda (2019) where WAC of Indian bee pollen varied from $0.47 \pm 0.05$ (coriander bee pollen) to $0.72 \pm 0.08$ (coconut bee pollen). However, WAC of sunflower bee pollen recorded in this study has a lower value compared to that registered for all examined samples of bee pollen $(0.92-2.25 \mathrm{~g} / \mathrm{g})$ in the study previously
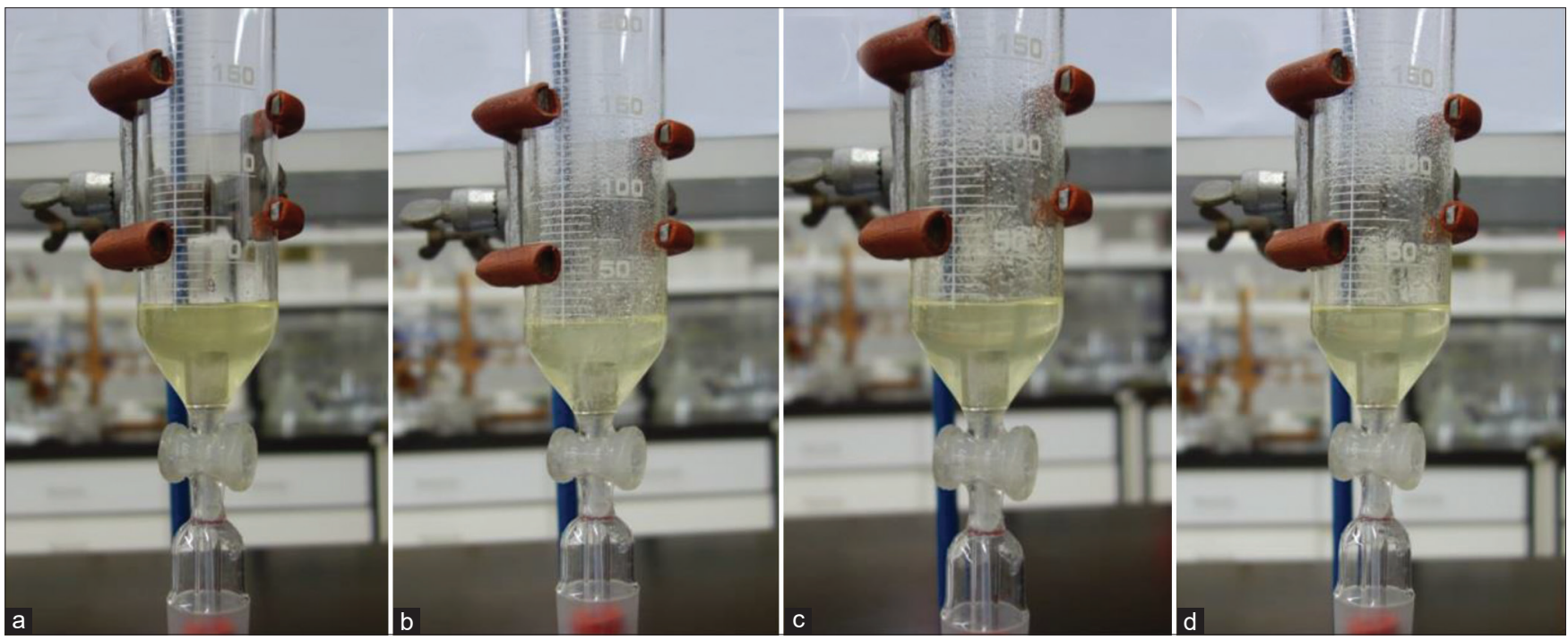

Fig 5. Methodological approach in determining of foaming properties of bee-collected sunflower (Helianthus annuus L.) pollen: (a) aqueous dispersion of pollen sample; (b) process of injection stream of air $(6 \mathrm{dm} 3 / \mathrm{min})$ in the sample during $15 \mathrm{~s}$ through a Waters filter holder in the sample; (c) foaming capacity after $15 \mathrm{~s}$ of constant injection of air; (d) foaming stability after 3 min. 
reported by Kostić et al. (2015b). These differences could be due to a number of factors which influence water uptake such as the composition/conformation (i.e., available hydrophilic groups) of the proteins, the presence of sugars (i.e., hydrophilic polysaccharides), lipids (i.e., polar lipids with their polar and charged regions) and salts (Kinsella and Melachouris, 1976; Kostić et al., 2015b). Furthermore, it is suggested (Kostić et al., 2015b) that the three-dimensional structure of macromolecules such as proteins and insoluble polysaccharides contribute to the binding of water molecules by capillary action, while on the other hand, intermolecular bonding via ionic bonds decreases hydration (Kinsella and Melachouris, 1976).

\section{Oil absorption capacity}

The ability of food compounds to absorb oil is an essential feature of the food product for its acceptability, since lipids act as flavour retainers and enhancers of the mouth feel (Kinsella and Melachouris, 1976). The monofloral sunflower bee pollen showed high oil absorption capacity (OAC) $(2.43 \pm 0.02 \mathrm{~g} / \mathrm{g}$ ) (Table 3$)$. This value is in the range of previously published results by Kostić et al. (2015b) $(1-3.53 \mathrm{~g} / \mathrm{g})$, while it is higher than the values reported by Thakur and Nanda (2019) (1.31-2.13 g/g). Furthermore, the obtained result is significantly higher than those previously recorded for chickpea (Peredes-Lopez et al., 1991), pea and soy (Fernandez-Quintela et al., 1997) protein isolates. Excellent oil absorption capacity of bee pollen was already observed and attributed to the complex polymer sporopollenin, major component of pollen exine, the presence of hydrophobic parts of proteins or other insoluble components (Kostić et al., 2015b; Thakur and Nanda, 2019). The water/oil adsorption index of analysed pollen sample was $0.357 \pm 0.001$. This value is in accordance with previously published data for WOAI of pollen samples of different origin (Kostić et al., 2015b; Thakur and Nanda, 2019), which highlighted again the better lipophilic than hydrophilic characteristics of beecollected pollen.

\section{CONCLUSIONS}

The obtained monofloral bee-collected sunflower pollen exhibited desirable properties regarding to possible application in food formulation. Namely, sugars, lipids and proteins as the main macronutrients were presented in high quantity with predominance of sugars. This provided high energetic value for pollen- $400 \mathrm{kcal} / 100 \mathrm{~g}$. In addition, Raman spectroscopy has proved that pollen can be used as good source of carotenoids, an important phytochemicals. Practical application of $0.1 \%$ pollen suspension as emulsifier in realistic system has demonstrated its excellent emulsifying properties expressed as emulsifying stability and activity indices. The obtained values were in range with some protein isolates previously recognized as good emulsifiers. Despite to low lipids content the examined sample had good oil absorption capacity which can be related to existence of sporopollenin as well as hydrophobic parts of protein molecules which were presented in significant quantity. In addition, the prepared pollen suspension exhibited non-foaming properties which are also desirable for some food systems. In order to determine precise ranges for emulsifying properties and to make some recommendation further investigation of different monofloral bee-collected pollen samples is needed.

\section{Author's contribution}

A.Ž. Kostić, D.D. Milinčić and M.B. Pešić conceptualized research, performed analysis and wrote Manuscript; S. Lević wrote part of Manuscript and performed FTIR and Raman analysis; B.D. Špirović-Trifunović performed GC analysis; S.P. Stanojević performed chemical analysis; N. Nedić collected pollen and performed palynological analysis; V. Nedović, M.B. Pešić and Ž. Lj. Tešić provided funding and critically reviewed Manuscript.

\section{CONFLICTS OF INTEREST}

There are no conflicts to declare.

\section{ACKNOWLEDGEMENTS}

This research was funded by the Ministry of Education, Science and Technological Development of the Republic of Serbia through Contract No. 451-03-68/2020-14/200116. Authors would like to give thanks to Vladimir Kostić on graphical Abstract preparation.

\section{REFERENCES}

Anjos, O. A. J. Santos, T. Dias, and T. M. Estevinho. 2017. Application of FTIR-ATR spectroscopy on the bee pollen characterization. J. Apic. Res. 56: 210-218.

Avni, D., H. P. Hedriksma, A. Dag, Z. Uni, and S. Shafir. 2014. Nutritional aspects of honey bee-collected pollen and constraints on colony development in the eastern Mediteranean. J. Insect Physiol. 69: 65-73.

Barać, M., S. Čabrilo, M. Pešić, S. Stanojević, S. Žilić, O. Maćej, and N. Ristić. 2010. Profile nad functional properties of seed proteins from six pea (Pisum sativum) genotypes. Int. J. Mol. Sci. 11: 4973-4990.

Barać, M., S. Čabrilo, S. Stanojević, M. Pešić, M. Pavlićević, B. Zlatković, and M. Janković. 2012. Functional properties of protein hydrolysates from pea (Pisum sativum) seeds. Int. J. Food Sci. Technol. 47: 1457-1467.

Barać, M. B., M. B. Pešić, S. P. Stanojević, A. Ž. Kostić, and V. Bivolarević. 2015. Comparative study of the functional properties of three legume seed isloates: Adzuki, pea and soy 
bean. J. Food Sci. Technol. 52: 2779-2787.

Belina-Aldemita, M. D., C. Opper, M. Schreiner, and S. D'Amico. 2019. Nutritional composition of pot-pollen produced by stingless bees (Tetragonula biroi Friese) from the Philippines. J. Food Compos. Anal. 82: 103215.

Boye, J., F. Zare, and A. Pletch. 2010. Pulse proteins: Processing, characterization, functional properties and applications in food and feed. Food Res. Int. 43: 414-431.

Buta, E., M. Cantor, R. Ştefan, R. Pop, I. Jr. Mitre, M. Buta, and R. E. Sestraş. 2015. FT-IR characterization of pollen biochemistry, viability, and germination capacity in Saintpaulia H. Wendl. genotypes. J. Spectrosc. 2015: 706370.

Campos, M. G. R., S. Bogdanov, L. B. Almeida-Muradian, T. Szczesna, Y. Mancebo, C. Frigerio, and F. Ferreira. 2008. Pollen composition and standardisation of analytical methods. J. Apic. Res. 47: 154-161.

Conti, I., P. Medrzycki, C. Argenti, M. Meloni, V. Vecchione, M. Boi, and M. G. Mariotti. 2016. Sugar and protein content in different monofloral pollens buildings a database. B. Insectol. 69: 318320.

Culbertson, J. F. 2005. Food protein functionality. In: Handbook of Food Science, Technology, and Engineering. Vol. 4., $1^{\text {st }}$ ed. CRC Press, Boca Roton, Florida, USA.

Dalgleish, D. G. 1997. Adsorption of protein and the stability of emulsions review. Trend. Food Sci. Technol. 8: 1-6.

Depciuch, J., I. Kasprzyk, E. Roga, and M. Parlinska-Wojtan. 2016. Analysis of morphological and molecular composition changes in allergenic Artemisia vulgaris L. pollen under traffic pollution using SEM and FTIR spectroscopy. Environ. Sci. Pollut. Res. 23: 23203-23214.

Dobson, H. E. M. 1998. Survey of pollen and pollenkitt lipids-chemical cues to flower visitors? Am. J. Bot. 75: 170-182.

Evans, M., I. Ratcliffe, and P. A. Williams. 2013. Emulsion stabilisation using polysaccharide-protein complexes. Curr. Opin. Colloid In. 18: 272-282.

Fernandez-Quintela, A., M. T. Macarulla, A. S. Del Bario, and J. A. Martinez. 1997. Composition and functional properties of protein isolates obtained from commercial legumes grown in northern Spain. Plant Food. Hum. Nutr. 51: 331-341.

Foegeding, E. A., and J. P. Davis. 2011. Food protein functionality: A comprehensive approach. Food Hydrocolloid. 25: 1853-1864.

GB/T 19330. 2003. Product of Designations of Origin or Geographical Indication-Raohe (Northeast China Black Bee) Honey, Royal Jelly, Propolis, Bee Pollen. General Administration of Quality Supervision. Inspection and Quarantine of the People's Republic of China, Beijing, China.

Gould, J. M., S. Furse, and B. Wolf. 2016. The role of endogenous lipids in the emulsifying properties of cocoa. Front. Chem. 4: 11.

Guedes, A., H. Ribeiro, M. Fernández-González, M. J. Aira, and I. Abreu. 2014. Pollen Raman spectra data base: Application to the identification of airborne pollen. Talanta. 119: 473-478.

Ischebeck, T. 2016. Lipids in pollen they are different. Biochim. Biophys. Acta. 1861: 1315-1328.

Karakashev, S. I., and M. V. Grozdanova. 2012. Foams and antifoams. Adv. Colloid Interfac. 176-177: 1-17.

Kieliszek, M., K. Piwowarek, A. M. Kot, S. Błažejak, A. ChlebowskaŚmigiel, I. Wolska. 2018. Pollen and bee bread as new healthoriented products: A review. Trend Food Sci. Technol. 71: 170180.

Kinsella, J. E. and N. Melachouris. 1976. Functional properties of proteins in foods: A survey. Crit. Rev. Food Sci. 7: 219-280.
Kostić, A. Ž., M. B. Barać, S. P. Stanojević, D. M. Milojković-Opsenica, Ž. Lj. Tešić, B. Šikoparija, P. Radišić, M. Prentović and M. B. Pešić. 2015b. Physicochemical composition and technofunctional properties of bee pollen collected in Serbia. LWT Food Sci. Technol. 62: 301-309.

Kostić, A. Ž., M. P. Mačukanović-Jocić, B. D. Š. Trifunović, I. Ž. Vukašinović, V. B. Pavlović, and M. B. Pešić. 2017. Fatty acids of maize pollen quantification, nutritional and morphological evaluation. J. Cereal Sci. 77: 180-185.

Kostić, A. Ž., M. B. Pešić, M. D. Mosić, B. P. Dojčinović, M. M. Natić and J. Đ. Trifković. 2015a. Mineral content of bee pollen from Serbia. Arch. Ind. Hyg. Toxicol. 66: 251-258.

Krell, R. 1996. Value-added products from beekeeping. FAO Agric. Serv. Bul. 124: 87-113. Available from: http://www.apiterapia.biz/ pliki/value_added_products.pdf.

Liang, M., P. Zhang, X. Shu, C. Liu and J. Shu. 2013. Characterization of pollen by MALDI-TOF lipid profiling. Int. J. Mass Spectro. 334: 13-18.

Nicolson, S. W. and H. Human. 2013. Chemical composition of the "low quality" pollen of sunflower (Helianthus annuus, Asteraceae). Apidologie. 44: 144-152.

OGRS. 2013. Rulebook on Quality and other Requirements for Honey, other Bee Products and Products Based on Honey and other Bee Products. Official Gazette of Republic of Serbia No. 45: Paragraph 31, Serbian.

Peredes-Lopez, O., C. Ordorica-Falomir, and M. R. Olivares-Vazquez. 1991. Chickpea protein isolates: Physicochemical, functional and nutritional characterization. J. Food Sci. 56: 726-729.

Phillips, L. G., J. M. Davis and J. E. Kinsella. 1989. The effects of various milk proteins on the foaming properties of egg white. Food Hydrocolloid. 3: 163-174.

Schulte, F., J. Lingott, U. Panne, and J. Kneipp. 2008. Chemical characterization and classification of pollen. Anal. Chem. 80: 9551-9556.

Schulz, H. and M. Baranska. 2007. Identification and quantification of valuable plant substances by IR and Raman spectroscopy. Vib. Spectrosc. 43: 13-25.

Serra-Bonvehí, J. and R. E. Jordá, 1997. Nutrient composition and microbiological quality of honeybee collected pollen in Spain. J. Agric. Food Chem. 45: 725-732.

Taha, E. K. A., S. Al-Kahtani and R. Taha. 2019. Protein content and amino acids composition of bee-pollens from major floral sources in Al-Ahsa, eastern Saudi Arabia. Saudi J. Biol. Sci. 26: 232-237.

Thakur, M. and V. Nanda. 2019. Exploring the physical, functional, thermal, and textural properties of bee pollen from different botanical origins of India. J. Food Process Eng. 42: e12935.

Thakur, M. and V. Nanda. 2020. Composition and functionality of bee pollen: A review. Trend. Food Sci. Technol. 98: 82-106.

Wang, J. C. and J. E. Kinsella. 1976. Functional properties of alfalfa leaf protein: Foaming. J. Food Sci. 41: 498-501.

Wiercigroch, E., E. Szafraniec, K. Czamara, M. Z. Pacia, K. Majzner, K. Kochan, A. Kaczor, M. Baranska. 2017. Raman and infrared spectroscopy of carbohydrates: A review. Spectrochim. Acta A Mol. Biomol. Spectrosc. 185: 317-335.

Withnall, R., B. Z. Chowdhry, J. Silver, H. G. M. Edwards and L. F. C. de Oliveira. 2003. Raman spectra of carotenoids in natural products. Spectrochim. Acta A Mol. Biomol. Spectrosc. 59: 2207-2212.

Wolters-Arts, M., W. M. Lush and C. Mariani. 1998. Lipids are required for directional pollen-tube growth. Nature. 392: 818-821. 
Zimmermann, B. and A. Kohler. 2014. Infrared spectroscopy of pollen identifies plant species and genus as well as environmental conditions. PLoS One. 9: e95417.

Zimmermann, B., M. Bağcioğlu, C. Sandt and A. Kohler 2015. Vibrational microspectroscopy enables chemical characterization of single pollen grains as well as comparative analysis of plant species based on pollen ultrastructure. Planta. 242: 1237-1250.

Zinkl, G. M. and D. Preuss. 2000. Dissecting arabidopsis pollenstigma interactions reveals novel mechanisms that confer mating specifity. Ann. Bot. 85: 15-21. 